\title{
O turismo acessível como vantagem competitiva: implicações na imagem do destino turístico
}

\author{
Matthew Smith* \\ The University of Georgia, USA \\ Ericka Amorim** \\ Universidade de Nova de Lisboa (UNL), Portugal \\ Cláudia Soares*** \\ Universidade Federal Fluminense, Brazil
}

\begin{abstract}
Resumo: A imagem dos destinos turísticos está comumente associada aos seus atributos naturais e culturais e às suas vantagens em relação aos demais destinos. Com a crescente eclosão do número de destinos é natural o aumento da competitividade entre eles, procurando cada vez mais criar estratégias eficientes para posicionar e comunicar os seus atributos. Para discutir a impressão que se tem dado ao Turismo Acessível (TA), optou-se por discutir a questão da necessidade de adaptação dos espaços, frente as características da demanda atual e de como essas informações são registradas para os turistas.

$\mathrm{O}$ debate central deste documento visa abordar a questão do TA como atendimento às demandas da actualidade e a imagem do destino. Para tal, é imprescindível a compreensão da Tourism Destination image ou brand image, a imagem do destino.
\end{abstract}

Palavras-chave: Imagem do destino; turismo acessível; comunicação do destino;

The accessible tourism as a competitive advantage: implications in the image of destination

Abstract: The image of destinations in tourism is usually related to their natural and cultural elements and also to their advantages in relation to the others. Having in mind the exponential nunber of destinations it's quite reasonable that the degrre of competion between them develops all sorts of stategies in order to reveal their own value. To discuss the idea of Turismo Accessível means to think about the question of the need to adapt spaces, emphazising the aspect of the present requests and also the way the available informations can be useful to tourists.

The aim of this document is then to show the fact that AT answer to present requests as well as corresponds to the image of a specific destination, a fact that leads us to the question of the meaning of the expressions "Tourism Destination image" or "brand image", "the image of a destination as we will designed it from now on.

Key Words: Accessible tourism; Competitive advantage; brand image;

* University of Georgia, USA - Email: mls_health@comcast.net

* Universidade Nova de Lisboa. Portugal

* Universidade Federal Fluminense, Brasil 


\section{Introdução}

A imagem dos destinos turísticos está comumente associada aos seus atributos naturais e culturais e às suas vantagens em relação aos demais destinos. Com a crescente eclosão do número de destinos é natural o aumento da competitividade entre eles, procurando cada vez mais criar estratégias eficientes para posicionar e comunicar os seus atributos. Para discutir a impressão que se tem dado ao Tutirmos Acessível (TA), optou-se por discutir a questão da necessidade de adaptação dos espaços, frente as características da demanda atual e de como essas informações são registradas para os turistas. $\mathrm{O}$ debate central deste documento visa abordar a questão do TA como atendimento às demandas da atualidade e a imagem do destino. Para tal, é imprescindível acompreensão da Tourism Destination image ou brand image, a imagem do destino, como chamaremos daqui em diante.

$\mathrm{O}$ TA tem comummente sido discutido numa perspectiva social, na qual pretende-se garantir que as estruturas e serviços turísticos atendam adequadamente aqueles turistas que possuem algum tipo de limitação, seja ela temporária ou permanente. Desse ponto-de-vista, o turismo acessível é uma questão de justiça e igualdade, uma questão de inclusão daqueles que, muitas vezes, são marginalizados na nossa sociedade. No entanto, escapando à discussão que cabe à esfera da inclusão social, alguns estudos actuais apontam que o turismo acessível é economicamente interessante para a indústria e que, afinal, estar preparado para atender estes turistas pode significar muito mais do que o jargão socialmente correto de "fazer a nossa parte".

Por outro lado, a corrida para atrair este público específico deve ser cuidadosamente planejada. É preciso reflectir a melhor forma de comunicar e atrair este público. Enquanto vantagem competitiva, o TA apresenta-se como um diferencial de um destino com relação aos seus concorrentes. Enquanto segmento de mercado, seria reconhecido que há uma quantidade considerável de pessoas, com características semelhantes e que, para este público, deve haver um produto específico para atender aos seus desejos e necessidades. Ora, aqui apresentamos o cerne da discussão. Uma vez que a imagem promovida seja de um destino acessível, quais as implicações para este destino? Promover um destino acessível atrai o público deste segmento, mas é essa percepção (e imagem) que realmente pretende-se promover no mercado em geral? Quais as consequências da veiculação desta imagem entre o público do TA e entre os segmentos de mercado?
O principal objectivo deste artigo é discutir as implicações da promoção do Turismo Acessível na imagem dos destinos turísticos.

\section{Desmistificando o turismo acessível e seu impacto na imagem dos destinos turísticos}

Qualquer pessoa hoje saudável pode estar amanhã sujeita a algum tipo de limitação temporária ou permanente. $\mathrm{O}$ aumento da expectativa de vida da população, uma tendência mundial, também traz consigo o aumento das chances de adquirir alguma limitação que, fatalmente, é mais frequente à medida que avançamos na idade (Cole e Morgan, 2010, citado por Umbelino et. al., 2012). Com base nisso, o mercado do turismo acessível tem-se destacado como uma boa oportunidade na indústria do turismo. Enquanto uma boa parte da oferta turística ainda se apega aos aspectos ligados à responsabilidade social, oferecendo apenas o que é necessário, outra parte (ainda que a minoria) já reconhece as vantagens do turismo acessível enquanto negócio.

O turismo acessível pretende possibilitar que pessoas com alguma necessidade específica, incluindo dimensões de acesso relativas à mobilidade, visão, audição e cognição, consigam desempenhar as suas funções de forma independente e com igualdade e dignidade através de produtos, serviços e ambientes turísticos adequados (Buhalis and Darcy, 2011: 10-11). O turismo acessível inclui, portanto, não apenas os turistas com limitações permanentes (seja ela física, visual ou idosas, por exemplo), mas também aquelas pessoas que possuem algum tipo de limitação temporária (como as mulheres grávidas, uma pessoa com uma perna quebrada, etc.), reconhecendo que a mesma rua que dificulta/impende o deslocamento de uma pessoa deficiente também representa uma barreira para uma pessoa que usa muletas (Shimosakai, 2011).

Muito além das questões de ordem social, o mercado de TA destaca-se numa perspectiva de mercado. O número crescente de consumidores associados ao envelhecimento da população mundial mas também à mudança de paradigmas de consumo, identificando nestes consumidores que antes permaneciam em torno dos seus ambientes habituais, a motivação de sair para viver novas experiências e de forma cada vez mais independente. Estima-se que mais de 650 milhões de pessoas possuem alguma deficiência, o que significa $10 \%$ da população mundial, ou clientes em potencial para o mercado do TA. No contexto do turismo, estima-se que cerca de $7-8 \%$ dos visitantes internacionais tenham alguma limitação (Darcy et al., 
2008). O turismo mundial ultrapassou 1 bilhão de turistas, em Dezembro de 2012, (WTO, 2013), o que permite calcular que o número de turistas de TA é de cerca de 70 a 80 milhões.

Já um Estudo da Universidade de Surrey aponta que o potencial do mercado de TA é de cerca de 134 milhões de potenciais clientes (cerca de $27 \%$ da população Europeia), com receitas potenciais anuais de cerca de 83 mil milhões de euros (ENAT, 2007). Considerando que em 2012 o turismo internacional gerou US $\$ 1075$ bilhões (WTO, 2013), o que também permite avaliar que o TA, especificamente, gerou pelo menos US $\$ 75$ bilhões. Na Europa, os seniores (maiores de 65 anos) representam 72 milhões, dos quais 36 milhões viajam gerando receitas anuais de 34 bilhões de euros (Sá, Olão e Pereira, 2011: 44).

Com relação ao perfil do público do TA, tratam- se de turistas que viajam acompanhados, o que significa que os números apresentados podem aumentar consideravelmente. Somente $29 \%$ dos turistas com alguma deficiência viajam sozinhos - um mercado com uma média de 70 milhões de turistas pode, portanto, facilmente alcançar os 120 milhões de turistas. (Legacies Now, 2010). Estudos realizados para os Jogos Paralímpicos de Londres 2012 concluem que as pessoas com deficiências tendem a não viajar sozinhas e são frequentemente acompanhadas por algum profissional especializado, familiares ou amigos. Dos acompanhados, mais de 50\% viaja com o companheiro, $20 \%$ com o filho e 21 a $25 \%$ com um assistente, promovendo um aumento nos gastos com alojamento em mais de 25\% (DCMS, 2010; FMET, 2004: 13).

A realidade do mercado de TA é ainda a oferta de produtos/serviços com baixa qualidade e não adequados às necessidades do turista. Com relação aos destinos turísticos, ainda são poucos aqueles que conseguem atender a este público e, verifica-se, portanto, uma concorrência ainda pouco agressiva (King, 2009). Vantagens são muitas, estes turistas possuem mais tempo e são mais propensos a viajar a baixa estação, o que pode ajudar a diminuir os efeitos da sazonalidade, possui mais tempo e, em média, permanece mais no destino; possui um gasto médio superior à média; forte tendência à fidelização quando satisfeitos com o produto/serviço encontrado, até mesmo pela dificuldade actual de encontrar oferta adequada.

$\mathrm{Na}$ realidade, ainda não há números precisos nesta área mas todas as estimativas apontam para um mercado economicamente interessante e que deve ter a atenção da indústria não meramente por questões de responsabilidade social mas por gerar recursos. Acredita-se que se hoje a maior parte dos equipamentos e serviços turísticos cum- pre apenas requisitos exigidos por lei, em breve se tornará uma corrida para atender os desejos e necessidades de um público que tem dinheiro, tempo e desejo de viajar (Chan, 2010; Buhalis and Darcy, 2011; FMET, 2004; DCMS, 2010).

Portanto, trata-se de uma oportunidade vantajosa para os destinos que se declaram acessíveis e/ ou friendly com essa demanda, e por essa razão muitos buscam veicular essa imagem ao seu potencial público. A imagem que os destinos desejam construir em torno da tarefa de ser acessível é o principal ponto que compreende o presente debate. $\mathrm{O}$ atendimento às questões de natureza social $\mathrm{e}$ a evidente e crescente vantagem económica associada pretendem transformar esse segmento ora em vantagens na busca de novos turistas, ora se decalaram como uma oportunidade a um segmento de mercado com demandas específicas.

\section{TA enquanto vantagem competitiva}

Competitividade é uma competência para, a partir de recursos diversos, obtêm um resultado reconhecido e valorizado pelos públicos-alvo a que se destina em vantagem ou desvantagem face os demais concorrentes. (OCDE, 2007 in Azevedo e Duarte, 2010). A competitividade e sustentabilidade do produto está diretamente ligada à Teoria das Vantagens Competitivas, idealizada por Porter (1990). Essa teoria ajuda a explicar como alguns países ganharam vantagens competitivas em setores específicos. As vantagens comparativas têm perdido peso, uma vez que, cada vez mais, as dotações iniciais de recursos das nações, só por si, não constituem um fator decisivo para o desenvolvimento.

Quando se fala em competitividade de destinos turísticos, deve-se ter em consideração também o público. Hoje, os turistas são mais exigentes, até mesmo pela vasta quantidade de oferta e acesso à informação, querem viver novas experiências, estão atentos à relação entre o preço e a qualidade, assim como estão atentos à questão de responsabilidade social e ambiental. Mas o que é competitividade? Na esfera organizacional, a competitividade envolve a capacidade de oferecer produtos e serviços de forma tão ou mais eficaz e eficiente que os concorrentes principais, gerando lucro para a empresa e benefício e satisfação para o cliente. Considerando os destinos turísticos, deve-se acrescentar a figura dos residentes. Pode, portanto, ser definido que um destino turístico competitivo tem a capacidade de oferecer um produto/serviço tão ou mais eficiente que os concorrentes, gerando lucro para o destino e satisfação para o turista e, subentendendo que o "lucro" 
pode vir em forma de benefícios para a comunidade, como geração de emprego, renda e melhoria da qualidade de vida da população, ou seja, tendo sempre em conta a sustentabilidade do destino (Blunck, 2006 in Azevedo, Magalhães e Duarte, 2010: 34; Kotler, 2000; Dwyer e Kim, 2003).

Assim, oferecer um produto/serviço de qualidade, que satisfaça e/ou supere as expectativas do turista pode proporcionar uma situação de vantagem com relação à concorrência, promovendo a fidelização e indicação a outros clientes. Os conceitos de vantagem comparativa e vantagem competitiva também foram aplicados ao turismo. Enquanto o primeiro conceito, a vantagem comparativa, está relacionado com a abundância de recursos naturais de um determinado destino (como o clima, os recursos históricos e naturais), o segundo, a vantagem comparativa, tem a ver com a capacidade de um determinado destino em agregar valor ao seu produtos/serviço. No caso da vantagem competitiva, como o caso das infra-estruturas turísticas, os festivais e eventos, as políticas governamentais, etc. (Firmino, 2007; Ritchie e Crouch, 1993).

Sá et.al (2011: 52) complementam o conceito de vantagem competitiva ao afirmarem que “... no posicionamento de uma localidade não basta querer; é necessário poder. Ter características adequadas. Distintivas. Únicas ou quase. De outro modo não se criam vantagens competitivas" e acrescentam que uma "vantagem competitiva sustentável existe quando uma empresa tem uma vantagem comercial de longo prazo comparativamente às empresas rivais". (Sá et al, 2011: 57). Assim, em termos de competitividade, o sucesso dos destinos turísticos dependem cada vez menos das vantagens comparativas preexistentes e é cada vez mais dependente das vantagens competitivas criadas. Quando o TA é uma vantagem competitiva ou um segmento de mercado? Quais as implicações deste posicionamento na promoção face à percepção e imagem do destino?

\section{Imagem dos destinos turísticos}

A ótica da vantagem competitiva permite compreender a imagem do destino turístico na comercialização e na satisfação do dos turistas. $\mathrm{O}$ atendimento a demandas de consumo pode fazer diferença na escolha do destino da viagem. Por isso destacam-se a importância da qualidade do destino e das ações promocionais deste em atenção sobretudo a adequação ao TA. É importante compreender que a imagem do destino turístico está diretamente relacionada não apenas com os aspectos promocionais do local mas também com a imagem e correspondência da expectativa e a realidade encontrada pelo turista ao eleger um determinando destino. A percepção então influirá tanto na eleição quanto na satisfação que terão numa viagem.

Quanto maior e melhor for a informação sobre o destino, melhor correspondência terá a imagem com a realidade. Quanto melhor essa relação, melhor e mais forte a imagem da cidade e a experiência do turista no local. Para compreensão da imagem do destino turístico, é necessário abordar essas questões. O produto global que se constituiu o destino turístico como todos os seus subprodutos e facilidades, além da atmosfera da cidade e a ações de comunicação que este 'produto' detém e lança para os futuros consumidores. Quanto mais próxima uma da outra, mais real será a experiência. Outra variável que se deve levar em conta é a percepção do consumidor identificando se a imagem construída foi emitida e recebida corretamente pelos turistas em potencial.

Assim, temos a imagem do destino relacionada diretamente com a qualidade percebida. Essa amplitude relaciona as ações de comunicação e se baliza substancialmente na teoria das vantagens competitivas anteriormente discutida. No caso dos destinos turísticos é possível relacionarmos aos produtos globais que encontramos em todos eles. Os mesmos hotéis, restaurantes, serviços, taxas, facilidades e outras ofertas derivadas da globalização dos serviços. Por isso, a oferta de serviços TA, diretamente relacionada com as facilidades podem ser consideradas vantagens competitivas entre destinos e essa imagem pode estar relacionada ao que será comunicado como prioridade de serviços ao turistas.

A OMT analisa a importância da imagem do destino turístico e destaca que:

"la decisión de compra por parte del consumidor turista se guía por una cautela mayor que para otros bienes de consumo, ya que el riesgo percibido es más alto. En consecuencia, la imagen que exista en la mente del consumidor sobre un destino o un servicio concreto, será decisiva para el proceso de toma de decisión y afectará al tipo de vacaciones elegido, aunque dicha imagen no se corresponda con la realidad". (1998, 70)

Uma outra preocupação dos autores é com a validade da imagem, ou seja deve corresponder à realidade. Também deve ser real e efetiva. É preciso que o consumidor tenha confiança nas informações que recebe e essas devem corresponder a realidade e devem ser claras e simples. E acima de tudo devem despertar a intenção da visita. Para o autor Chris Cooper (1998) o destino turístico é uma experiência cultural. $\mathrm{O}$ autor compreende que a 
experiência do visitante é a soma das experiências de cada um dos serviços que o turista consumiu. Portanto a experiência é total do destino por ele escolhido e não fragmentada como pode parecer a viagem. Para muitos autores (Schmoll, Mathieson e Wall, Mouti nho, Woodside e Lysonsky, Um e Crompton, Goodall e Mansfield) a percepção dos turistas é fator determinante na construção da imagem do destino. Muitos estudos empíricos tem confirmado o papel da percepção como

"elemento casual no processo de criação das imagens que os indivíduos atribuem aos lugares e também são fatores condicionantes da decisão de compra". (GANDARA, 2008 http:// www.eca.usp.br/turismocultural/aimagem.pdf)

Segundo Coopere et al (1997: 30), a consciência individual do mundo é feita de experiências, aprendizado, emoções e percepções, ou seja, avaliação cognitiva de. Esta consciência pode descrever e como o conhecimento que produz uma imagem de mundo específica. Imagem obviamente afeta a preferência emotivação do indivíduo para o turismo, para proporcionar um efeito de "atracção" resultando diferentes padrões de demanda. A imagem é a causa da decisão da compra. Identificando a percepção dos turistas com relação a imagem do destino turístico é possível definir quais turistas são mais adequados aos referidos destinos e também promover as adaptações necessárias aos destinos com o objetivo de satisafazer as necessidades dos turistas.

A satisafação das necessidades dos turistas está diretamente ligada com a expectativa gerada perante as imagens que recebeu de determinando destino. E faz-se necessário que essas sejam as mais fiéis e correspondentes à realidade que o turista de fato encontrará no destino. Essa relação definirá, portanto, a qualidade que o turista atribuirá ao local e essas serão a medida da satisfação das expectativas geradas pelos turistas através da imagem que construiu com as informações que recebeu antes da viagem. A imagem será determinada pela percepção dos turistas que, por sua vez, estará afetada pela acessibilidade à cidade e pelas condições de qualidade de vida dos residentes. A clara interpretação do estilo de vida por parte dos visitantes e o ambiente que propicia o desenvolvimento do turismo, contribuem para a aceitação da imagem e para incrementar o poder de atração dos destinos (Melèndez, 1997). É regra entre os estudiosos que a utilização da imagem como um diferencial no mercado competitivo dos destinos turísticos é algo que cada vez mais importante. Criar uma imagem diferenciada é um instrumento básico para que o destino se posicione, com relação à sua competência, na mente dos consumidores. Para criar esta imagem diferenciada é importante identificar os elementos que são componentes do destino a serem destacados, já que estes serão seus grandes diferenciais. (Gandara, 2008)

Gândara (2008) ainda destaca que é fundamental que se estabeleça a imagem dos destinos turísticos e se destaquem as características que lhes possam diferenciar da concorrência. Ao caracterizar

"o destino com aspectos "únicos", este não somente terá mais possibilidades de atrair mais visitantes como estará mais protegido das tendências globalizadoras, já que seus diferencias servirão tanto como o componente da imagem do destino como da identidade da população, o que sem dúvida fortalecerá a imagem e consequentemente a comercialização do mesmo.”

Cada vez mais os turistas optam por destinos turísticos com qualidade diferenciada e com atenção a necessidades especiais e aspectos que possam dar-lhe a liberdade de escolha. Um destino turístico ter sua imagem relacionada a TA pode dar-lhes oportunidades de diferenciação e atração de visitantes que outros destinos não possuem, promovendo sobretudo a imagem relacionada a sustentabilidade e a aspectos relativos a responsabilidade social, o que nos dias atuais tem feito diferença para escolha de determinados grupos de consumidores. Essa percepção da seriedade e das necessidades específicas de cada grupo de turistas consumidores promove a real diferenciação do destino, que se torna capaz de competir num mercado cada vez mais preocupado com questões de natureza social e ambiental.

\section{Promoção do TA e a imagem dos desti- nos acessíveis}

No contexto actual, grande parte da oferta turística não está devidamente preparada para o público do TA e o destino que estiver preparado para atender essa demanda possui uma vantagem competitiva com relação aos demais destinos. A questão é, com base em que perspectiva deve-se promover o destino acessível? Obviamente, comunicar que possui essa vantagem em um mercado com grande potencial parece ser uma decisão acertada. No entanto, deve um destino posicionar-se (e vender-se) como um destino acessível?

Um ponto importante dessa discussão ronda a questão de que a acessibilidade em si, na maior parte das vezes não constitui um atractivo turístico. Dificilmente um turista irá deslocar-se a 
um determinado destino apenas pelo fato de possuir equipamentos e serviços adequados para o receber bem. Por outro lado, se o turista precisa destes equipamentos/serviços e o destino não o possui, pode ser uma razão suficiente para que o turista deixe de visitar o destino em questão. Em outra perspectiva, o turista viaja por uma motivação seja ela de lazer, cultural, negócios e considera as condições do destino, mas estas condições não constituem, em si, uma motivação de viagem. Portanto, construir a imagem do destino com base numa vantagem competitiva como a acessibilidade pode ser algo perigoso. Trata-se hoje de um diferencial e os destinos realmente preparados praticamente não encontram concorrência no mercado. Contudo, há uma tendência a adequação dos produtos/serviços ao mercado de TA, seja por razões sociais ou económicas.

Além disso, não se trata de uma vantagem competitiva de difícil superação, ou seja, é uma vantagem competitiva que só pode ser sustentada a curto e médio prazo. Numa perspectiva de longo prazo outros destinos poderão também ser acessíveis e, numa perspectiva otimista, é isso que espera-se. Seja com base em exigências legais, seja por reconhecimento de um mercado promissor e rentável, a tendência é que a oferta esteja cada vez mais preparada para atender bem o segmento do TA. Ou seja, acredita-se que num futuro não muito distante, a maioria dos destinos turísticos estará preparada para atender ao público do TA e, portanto, um destino que se posicionar exclusivamente nessa vantagem competitiva actual poderá encontrar problemas com a imagem veiculada.

Outro problema identificado com relação ao forte posicionamento como destino acessível recai sobre os outros segmentos de mercado. Como já foi discutido anteriormente, a imagem do destino está intimamente ligada ao conceito de percepção por parte do turista. A questão é, comunicar a acessibilidade como o principal atributo do destino deixa de lado as atractividades do destino, além de praticamente excluir do seu mercado-alvo os outros segmentos.

O turista de TA busca a inclusão num contexto de viagem em que possa vivenciar novas experiências e, ao mesmo tempo, encontrar equipamentos e serviços de qualidade que possibilite isso. $\mathrm{O}$ forte posicionamento em torno da acessibilidade passa a imagem de que o destino é exclusivamente ou majoritariamente voltado para este público em específico.

Alguns destinos actualmente se promovem como destinos acessíveis deixando de promover também os reais atractivos que possuem e, portanto, praticamente só atraem o público de TA porque é essa a imagem que se trabalha. Promove- -se a acessibilidade do destino, por ser uma mais-valia hoje, e esquece-se de promover os atractivos naturais, culturais, entre outros. Será mesmo isso que irá atrair esses turistas? E considerando que eles não viajam sozinhos, será apelativo suficiente para uma família? Outros segmentos turísticos frequentarão o seu destino? Os turistas do TA querem estar em um destino majoritariamente frequentado por pessoas com limitações?

\section{Considerações Finais}

O TA tem crescido seja por motivos de ordem social, onde reconhece-se a necessidade da inclusão social, seja por razões económicas, reconhecendo tratar-se de um público que gasta dinheiro, permanece mais tempo nos destinos e tem uma grande tendência à fidelização, por exemplo.

No entanto, ainda que constituam um público interessante, os destinos turísticos devem estar atentos ao tipo de imagem que veiculam. Se por um lado, a acessibilidade é uma mais-valia e, no contexto actual do mercado turístico, pode ser mesmo considerada uma vantagem competitiva, por outro lado, não se trata de uma vantagem sustentável a longo prazo e isso poderá vir a pôr em risco todos os esforços promocionais de um determinado destino.

Defendemos que os destinos acessíveis devem comunicar fortemente junto aos stakeholders e o público em geral a actual mais-valia de poder atender aos turistas do TA com equipamentos e serviços eficientes e de qualidade. Também defendemos que essa comunicação deve ocorrer de forma secundária e não constituindo o principal ponto da imagem do destino. Os destinos devem basear a sua imagem no que possuem de diferencial e que motivem os turistas a saírem de casa e os visitarem. Devem "vender" os seus atractivos naturais, culturais, as experiências únicas que podem oferecer. Devem ter cuidado, portanto, com relação entre a imagem que pretende realmente passar e a percepção dela por parte do público do TA e o público em geral. Vale reflectir: a imagem do seu destino é sedutora o suficiente para motivar o público de TA a sair de casa para desbravar o mundo?

\section{Referências}

Azevedo, A.; Duarte, M.; Pereira, J.

2010 "CityMarketing - My Place in XXI - Gestão Estratégica e Marketing de Cidades". Vida Económica, Porto.

Bercial, R. A.; Timón, D. 
2005 "Nuevas Tendencias en el Desarrollo de Destinos Turisticos: Marcos Conceptuales y Operativos para su Planificación y Gestión". Cuadernos de Turismo, España, p. 27-43.

Bolwell, D.; Weinz, W.

2008 Reducing Poverty Through Tourism. International Labour Office, Geneva.

Chan, Ho- Kai.

2010 Hotel Customer needs, satisfaction, and loyalty: analysis of travelers with disabilities in Taiwan. Lubbock: Texas Tech University, PhD Thesis in Philosophy.

Cooper, C., Fletcher, J., Gilbert, D., Wanhill, S. 2008 Turismo, princípios e práticas. São Paulo. Bookman.

Darcy, Simon and others.

"Developing business case studies for accessible tourism" CRC for Sustainable Tourism. http:// www.crctourism.com.au/bookshop/Search Result.aspx (2008, accessed June 07, 2011)

Dwyer, Larry; Kim, Chulwon

2003 "Destination Competitiveness: Determinants and Indicators",. Current Issues in Tourism, 6(5).

Firmino, Manuel Brazinha

2007 Turismo - Organização e Gestão. Escolar editora, Lisboa.

FMET - Federal Ministry of Economics and Technology.

2004 Economic Impulses of Accessible Tourism for all. Berlin: FMET.

Gandara, J. M.

2000 "La imagen de calidad ambiental urbana como atractivo turístico. El caso de Curitiba, Brasil". In: Estudios y Perspectivas en Turismo. Buenos Aires: Centro de Investigaciones y Estudios Turísticos.

Gandara, J. M. G.

(2008) http://www.eca.usp.br/turismocultural/ aimagem.pdf

Harrison, J.

2005 Administração Estratégica de Recursos e Relacionamentos. Ed. Bookman.

King, Sheila.

"Accessible Tourism: Big Business, yet undiscovered". http://www.tourism-review.com/accessible-tourism-big-business-yet-undiscovered-news1315. (2009, accessed June 07, 2011)

Kotler, P.

2000 Administração de Marketing. Prentice-Hall.

Legacies Now

2010 "Accessible Tourism Market Research". www.2010legaciesnow.com/accessible_tourism/ (2010, accessed April 04, 2011)

Lindon, D.

2004 Mercator XXI - Teoria e Prática do Marketing. Dom Quixote.
Mathias, A

2007 Economia do Turismo - Teoria e Prática. Instituto Piaget, Lisboa.

Meléndez U., Anaida

1997 Apuntes del módulo: "Patrimonio ambiental urbano como recurso turístico". In: Master Internacional de Turismo de la Universidad de Las Palmas de Gran Canaria. Las Palmas de Gran Canaria.

Middleton, V.

2010 Marketing de Turismo - teoria e prática. Elsevier.

Oraganización Mundial del Turismo

1998 Introducción al turismo. Madrid: Organización. Packer, Tanya and Carter, May.

"Out of the Blue! Valuing the disability market in tourism: Report of the 5th National Nican Conference, Perth, 20-22 September 2004". http://espace.library.curtin.edu. $\mathrm{au} / \mathrm{R}$ ?func $=$ dbin-jump - full\&local_base $=$ gen01-era02\&object_id=19328 (2004, accessed June 07, 2011)

Peixoto, N; Neumann, P.

2009 "Factores de Sucesso e Propostas de acções para implementar o Turismo para Todos. Relevância Económico-Social”. In: Revista Turismo \& Desenvolvimento, Universidade de Aveiro.

Ritchie, J. R Brent; Crouch, Geoffrey I.

1993 Competitiveness in International Tourism: a Framework for understanding and Analysis, Proceedings of the 43rd Congress of the Association Internacionaled'Experts Scientifique du Tourime, 17 - 23 October, San Carlos de Bariloche, Argentina.

Sá, J. V.; Olão, F.; Pereira, M.

2010 Drucker no Turismo: Criando "Battle-ready Organizations". Vida Económica, Portugal.

WTO - World Tourism Organization.

Declaration on the Facilitation of Tourist Travel. Madrid: World Tourism Organization, 2010

WTO - World Tourism Organization.

"Multi-speed recovery for international tourism in 2010". http://www.unwto.org/facts/eng/ barometer.htm (accessed April 04, 2011).

WTO - World Tourism Organization.

International Tourism Receipts grew by $4 \%$ in 2012. http://media.unwto.org/en/press-release/2013-05-15/international-tourism-receipts-grew-4-2012 (acessed, May, 28, 2013).

Recibido:

$16 / 05 / 2013$

Reenviado:

$16 / 06 / 2013$

Aceptado:

$01 / 07 / 2013$

Sometido a evaluación por pares anónimos 